\title{
RISKS FROM CHRONIC IRRADIATION AND THEIR
} HAEMATOLOGICAL CONTROL

\author{
BY
}

\author{
R. H. MOLE
}

From the Medical Research Council's Radiobiological Research Unit, Atomic Energy Research Establishment, Harwell

(RECEIVED FOR PUBLICATION MAY 17, 1954)

Although it is now standard practice to do periodic blood counts on people regularly exposed to radiation in the course of their work no criteria exist by which the amount of radiation damage or its severity can be assessed unambiguously from the blood picture. This sometimes makes the interpretation of the counts a difficult and anxious matter. My purpose here is to consider in a general way whether these blood counts can in fact ever serve the purpose for which they are intended, and to raise the question whether it is appropriate for the clinical pathologist to do them.

In the field of atomic energy a serious effort has been made to see that workers run no risk. It is impossible to prevent all exposure to irradiation, and safe working levels are usually expressed in terms of maximum permissible dose (m.p.d.) rates; their calculation is described by Neary (1952). The m.p.d. is the rate at which radiation may be received every working day throughout a lifetime without causing harm. This does not imply a complete absence of damage. The gardener's hands lose tactile sensitivity and may even develop a characteristic deformity from potting plants (Cohen,1947), but this amount of damage is accepted as not harmful. The m.p.d. takes into account not only the possibility of harm to the individual but also the possibility of harm to the race by reason of the genetic changes produced by radiation (Catcheside, 1950). The clinical pathologist, however, is concerned primarily with the individual, and this paper is concerned with the value of blood counts to the individual occupationally exposed to radiation.

When the "Recommendations for Radiation. Protection" were agreed upon internationally in 1931 changes in the blood count were regarded as more than just damage; they were considered as evidence of harm done to the individual (Recommendations of the International X-ray and Radium Protection Commission, 1932). By definition therefore exposure to the maximum permissible dose rate of radiation should not produce blood changes, and the value of blood counts would then be to detect over-exposure. Now exposure to radiation can be quantitatively measured by means of specially treated photographic films carried by the individual worker (film badges) or by radiation meters, so that blood counts should show changes only when working conditions allow of over-exposure, and be of value only when discipline fails and the worker does not carry his film. The clinical pathologist is then being called in to detect engineering and disciplinary failures. If we accept that this is an appropriate role for him to play we ought to make sure that his tests are sensitive enough to do the job.

\section{Changes in the Blood Count due to Radiation}

Fig. 1 shows schematically what patterns of change might be observed in some constituent of the blood during chronic exposure to irradiation. If the ability to repair were not damaged too much one might expect, as in (a), an initial drop, due to the destructive effect of radiation, without any

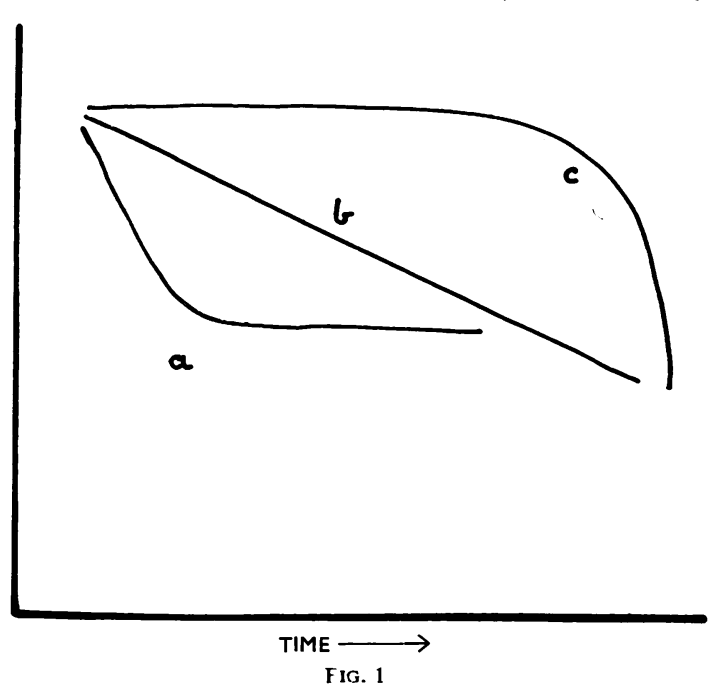


further decrease subsequently, since the rate of repair would then be able to keep up with the rate of destruction. If the ability to repair were damaged sufficiently one would expect a steadily progressive fall as in (b). And if repair could keep up with destruction until the ability to repair was exhausted, then a curve like (c) might be found. Clearly periodic checks on the blood could only be of use in detecting damage if the changes due to irradiation followed patterns $(a)$ or $(b)$ and it seems to have been tacitly assumed that there would be a progressive decrease as in $(b)$ with progressing damage.

\section{Experimental}

In actual fact the changes observed seem to follow one or other of the other two patterns (a) and $(c)$. For example, when mice were irradiated continuously the blood lymphocyte count dropped in the first few months and then remained steady at a fairly constant fraction of the control value (Lorenz, Eschenbrenner, Heston, and Uphoff, 1951). The neutrophils were not similarly decreased. No changes in the blood count, however, were detectable at levels of irradiation of 50 times the m.p.d.* (Lorenz, Heston, Jacobson, Eschenbrenner, Shimkin, Deringer, and Doniger, 1946). The dog is more sensitive to radiation, and Fig. 2 shows the changes

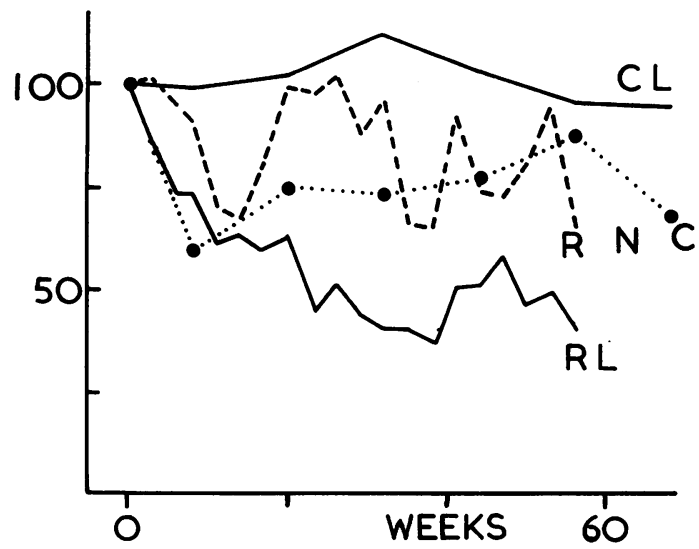

FIG. 2.-Effect of chronic $x$-irradiation on the white cell count of the $\operatorname{dog}(3 \mathrm{r}$ daily for one year). $\mathrm{C}=$ control, $\mathbf{R}=$ irradiated, $\mathbf{N}=$ neutrophil (heterophil), $\mathbf{L}=$ lymphocyte. Each count is given as a percentage of the initial control value. (Redrawn from data of Ingram and Mason, 1950.)

produced by 60 times the m.p.d. (Ingram and Mason, 1950). The lymphocyte count again followed pattern (a) of Fig. 1, and again this was a more sensitive indicator of radiation effects than the heterophil count, where there was no difference from the control group. Fig. 3 shows the changes

\footnotetext{
* In order to avoid introducing technical terms unnecessarily, all doses in this paper are given in multiples of the human maximum permissible dose rate $(0.05 \mathrm{r}$ daily).
}

in the guinea-pig, the most radio-sensitive animal haematologically speaking, irradiated at 80 and 20 times the m.p.d. (Lorenz et al., 1946). Neutrophil and lymphocyte counts were decreased to $50 \%$ below the controls at the higher dose rate, and to about $20 \%$ below at the lower dose rate, though this smaller change is only evident statistically. But white

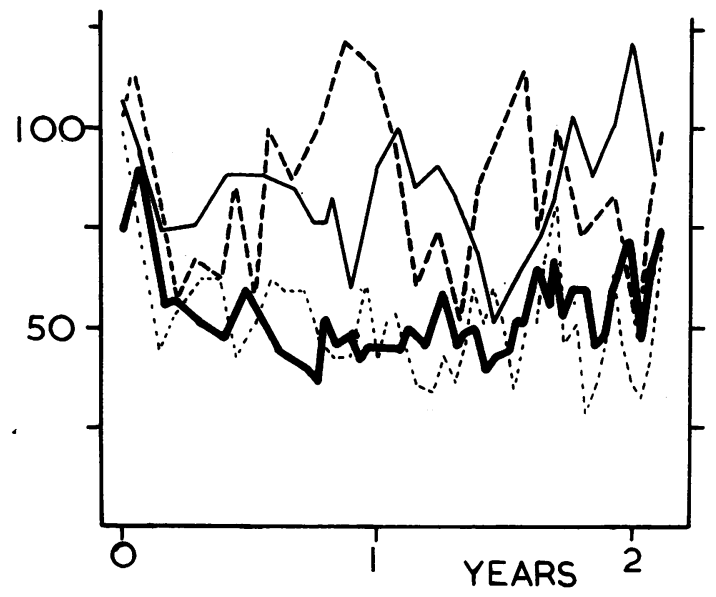

FIG. 3.-Effect of chronic irradiation on the white cell count of the guinea-pig. Continuous lines lymphocytes, broken lines heterophils. The two upper curves are from animals irradiated at $1.1 \mathrm{r}$ daily, the two lower curves are from animals irradiated at 4.4 $\mathrm{r}$ daily. The counts are given as percentages of the counts of unirradiated controls examined about the same time. (Redrawn from data of Lorenz and others, 1946.)

counts would have provided a poor control of irradiation hazards for these guinea-pigs. The mean drop of $20 \%$ below the control value is just detectable from inspection (Fig. 3), yet at the end of two years deaths among guinea-pigs exposed at this dose rate were double the controls and at the higher dose rate $75 \%$ of the whole group was dead. There was no progressive decrease in cell count to indicate increasing damage.

When applying these experimental findings to the clinical problem three things have to be borne in mind. The observed changes at 20 to 80 times the m.p.d. (Figs. 2 and 3) were clearly visible because groups of animals were used to establish the points: the changes would be much harder or impossible to detect with cartainty in a single individual, granted the inevitable and natural fluctuations between repeated counts. Next, weekly dose rates of 20 times the m.p.d. and more just should not occur where people work. And lastly in a variety of animals a lymphopenia has been at least as sensitive a sign of damage as a neutropenia, whereas the orthodox teaching is that the earliest quantitative change in men exposed to irradiation is a decrease in neutrophils without any change in the number of lymphocytes. 
Before considering the human evidence on which this view was based, the more serious haematological effects of irradiation will be illustrated. When a monkey is given radioactive strontium it localizes in the bones and irradiates the bone marrow continuously (Edington, Judd, and Ward, 1953). In such an animal the white count was unaffected even on the day of death (Fig. 4). There was a

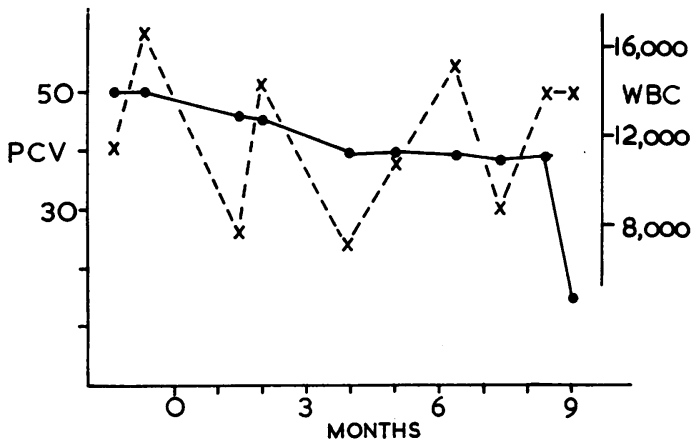

Fig. 4.-Packed cell volume (C- $)$ and total W.B.C. $(\times--\times)$ in a monkey given ${ }_{90} \mathrm{Sr}$ (Judd and Ward, 1954).

very slow fall in the haemoglobin and red count for nine months and then a quite suddenly developing and fatal anaemia. The pattern of change is of the third type $(c)$ of Fig. 1, and it is clear that in this case the white count gave no prior warning that the marrow was aplastic.

\section{Clinical}

The same seems to be true of the human cases of aplastic anaemia caused by radiation; in those too the white count gave no prior warning of what was to come. By the time the anaemia had become severe the white count was usually low (though not always; 4,700 leucocytes per c.mm. on the day of

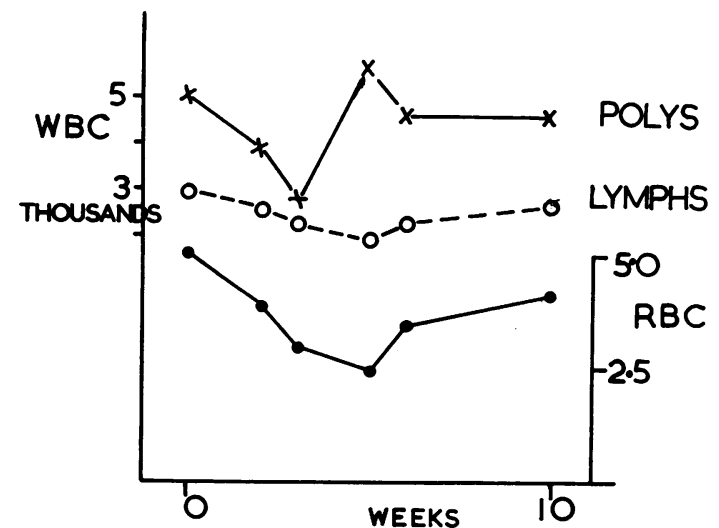

Fig. 5.-Serial blood counts in a non-fatal case of radiation anaemia. (Data from Carman and:Miller, 1924.) death in the case described by Emile-Weil and Lacassagne, 1925) as in aplastic anaemia from whatever cause, but anaemia and leukopenia developed quickly. In only a few of the cases of anaemia due to external radiation described in the literature (listed by Lambin, 1930) is information available about the blood picture shortly before the onset of the illness; the white count was then within normal limits (Table I and Fig. 5). Now it is historically true that it was these deaths from aplastic anaemia which initiated in this country the first agreed "Recommendations for Radiation Protection," later adopted internationally, and which made blood counts seem a most important protective measure. It seems clear, however, that it is unlikely that these tragedies would have been prevented by blood counts, though they would most certainly have been

TABLE I

BLOOD PICTURE SHORTLY BEFORE ONSET OF FATAL APLASTIC ANAEMIA IN THREE RADIATION WORKERS

\begin{tabular}{|c|c|c|c|c|c|c|}
\hline \multirow[b]{2}{*}{$\begin{array}{l}\text { Months before death } \\
\text { Haemoglobin (\%) .. } \\
\text { R.B.C. (m/c.mm.) } \\
\text { W.B.C. (thousands) }\end{array}$} & \multicolumn{2}{|c|}{$\begin{array}{l}\text { Case of } \\
\text { Larkins } \\
\text { (1921) }\end{array}$} & \multicolumn{2}{|c|}{$\begin{array}{l}\text { Case of } \\
\text { Faber } \\
\text { (1923) }\end{array}$} & \multicolumn{2}{|c|}{$\underset{\substack{\text { Mottram } \\
(1920)^{*}}}{\text { Case } A \text { of }}$} \\
\hline & $\begin{array}{c}5 \\
85 \\
4 \cdot 2\end{array}$ & $\begin{array}{c}1 \frac{1}{2} \\
54^{2} \\
2 \cdot 7\end{array}$ & $\begin{array}{c}10 \\
4 \cdot 6\end{array}$ & $\begin{array}{c}1 \\
56 \\
3.8\end{array}$ & $\begin{array}{r}9 \\
95\end{array}$ & $\begin{array}{r}2 \frac{1}{2} \\
45^{2} \\
2 \cdot 2\end{array}$ \\
\hline $\begin{array}{ll}\underset{\text { Total }}{\text { c.mm.) }} \quad . . & \ldots \\
\text { Neutrophils } & \ldots \\
\text { Lymphocytes } & \ldots\end{array}$ & $\begin{array}{l}7,200 \\
4,300 \\
2,700\end{array}$ & $\begin{array}{l}1,600 \\
300 \\
1,200\end{array}$ & $\begin{array}{c}5,000 \\
\text { Normal } \\
, "\end{array}$ & $\begin{array}{l}4,200 \\
2,400 \\
1,500\end{array}$ & $\begin{array}{l}3,900 \\
2,000 \\
1,700\end{array}$ & $\begin{array}{r}1,200 \\
590 \\
640\end{array}$ \\
\hline
\end{tabular}

* I am indebted to Mr. Burgh and Mount Vernon Hospital for the hitherto unpublished data of Mottram's case A. No early bicod counts are available on his other two cases. It is noteworthy that the last illness in all three cases described by Mottram (1920) was of short duration. This alone is not positive evidence that human illness follows pattern (c) of Fig. 1, but for Case A this was clearly true. She is stated to have been in excellent health during the whole of her eight years' occupational exposure and her illness began at the end of a two months' holiday.

prevented had any kind of physical monitoring of working conditions been available in those early days.

Mottram (1921) found a real neutropenia amongst hospital staff working in admittedly bad conditions of exposure, which improved when exposure to radiation was reduced. But the two individuals with really low neutrophil counts (500 and 1,000 per c.mm.) had low lymphocyte counts too (900 and 700 per c.mm.). In the three examples of the effects of work with radium which Mottram (1931) gave the fall in lymphocytes was proportionally greater than in neutrophils. At the time when he found these changes working conditions were bad enough to kill (Mottram, 1920), so that, although the radiation doses to which Mottram's subjects were exposed are unknown, they will have been many times the present-day m.p.d., i.e., as high as those experienced by animals showing similar changes. 
What was the evidence then that led to the orthodox teaching already mentioned, that neutropenia was the commonest early sign of over-exposure to radiation? The findings of the earlier workers will not be criticized, but this interpretation of their findings will be. In the last 20 years the standards of evidence in medicine have become considerably more stringent. Further, two important facts have only recently been fully appreciated: the considerable variability to be expected in doing serial white counts on an individual, and second the curious and still unexplained fact that, when a series of blood counts is made on an individual, there is often a progressive change in the white count so that the real baseline normal is not reached until after the first one or more counts have been done (Chamberlain, Turner, and Williams, 1952).

When it was first being realized that radiation might affect the blood count, any change whatsoever in someone exposed to radiation was naturally attributed to the radiations, so that monocytosis, eosinophilia, leukopenia, leucocytosis, anaemia, and polycythaemia, to mention only some of the findings, were all considered as evidence of radiation damage. This attitude may be illustrated in the work of Amundsen (1924), who found a "relative lymphocytosis" in a group of people working with radiation in a hospital. He expressed surprise that he found the same change in the hospital maids, the night nurse, and two medical students who had been working in the hospital for only a month, and concluded that this only showed how sensitive blood changes were to exposure to radiation. The alternative conclusion, that since the " abnormality" was found in those exposed to scarcely any radiation it did not signify radiation damage at all, was apparently not considered.

There was also too great a reliance on differential percentages. Lavedan (1929), for instance, described as showing " no change" progressive falls in total white count of 29 to $42 \%$ (his Cases 35 to 40 ), whereas a change of less than $10 \%$ in the proportion of neutrophils without a change in the total white count was often thought important (his Cases 1 to 7). There were always a few authors, for example, Barclay and Cox (1928), who failed to satisfy themselves that changes in the blood picture did occur in those working with radiation under conditions which were then thought reasonable but which would now probably be thought to give daily exposures at several times the m.p.d.

Ten years later after much propaganda occupational exposure in hospitals was considerably less. Nevertheless it was still believed that leukopenia was being produced. Fig. 6 includes a reproduction of Fig. 3A from Goodfellow (1935) giving the mean white count of people working with radium in Manchester. Twice over there appeared to be a progressive leukopenia when working conditions were bad with a return towards normal when these were improved. Goodfellow investigated 28 subjects altogether, but during the three years of the investigation these subjects were coming and going, so that different individuals contributed to the mean white count at different times. This would seem to make hazardous any deduction from changes in the group mean white count. Only four subjects in fact worked throughout the whole period, and when their mean white count is plotted (Fig. 6) there is no obvious change with worsening or improvement in working conditions. These were sufficiently bad at times for marked skin changes to have occurred in several subjects.



1932

1933

1934

1935

FIG. 6.-The lower curve is the mean white cell count (in thousand;) of all persons working with radium (redrawn from Goodfellow, 1935). The upper curve is the mean white cell count of the four individuals who worked with radium throughout the period (data from Goodfellow, 1935). The vertical lines indicate the two occasions when additions were made to the staff and duties were reorganized so as to reduce exposure to radiation. At the beginning of 1933 the hospital was enlarged, and this led to beginning of 1933 the hospital was enlarged, and this led to
progressively increasing work with radium, nullifying the effects of the first reorganization.

Goodfellow's other evidence for the leukopenic effects of radiation was the fall in the white count during the first few weeks of work with radium. Recently it has been shown (Chamberlain and others, 1952) that just such an initial fall in the neutrophil count is to be expected when serial counts are carried out on healthy individuals not exposed to irradiation at all. The lymphocyte count is not affected in this way. Thus an early fall in the white count and an increase in the percentage of lymphocytes cannot be considered evidence of radiation damage, as it was by Goodfellow and many other authors. It seems as if it is this early physiological 
fall in neutrophils which was responsible for the belief that exposure to radiation produced neutropenia. The same phenomenon is sometimes but not always seen in animal experiments (cf. Fig. 2).

One and only one of Goodfellow's subjects is recorded as having worked with excessive doses of radiation. His blood count during an experiment with 0.8 curie of radium is shown in Fig. 7 , and it

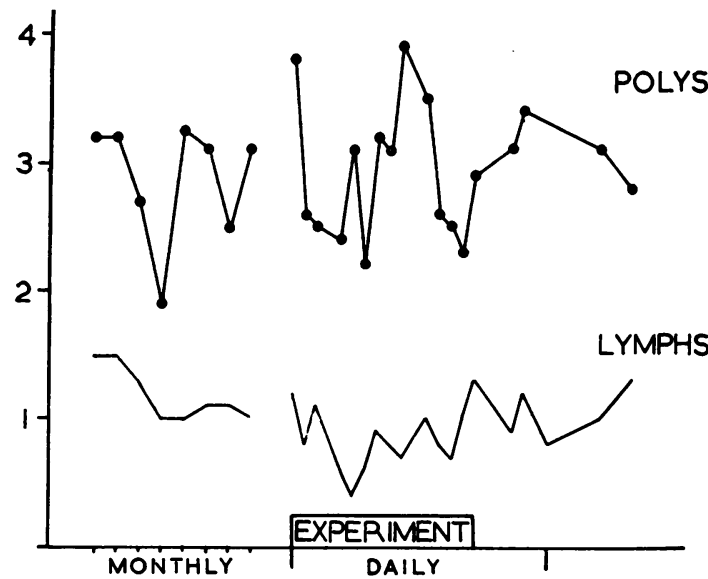

FIG. 7.-White cell counts (in thousands) of an individual doing an experiment with $800 \mathrm{mg}$. radium (data from Goodfellow, 1935).

is interesting that his lymphocyte count seemed to decrease during exposure while his neutrophil count did not. This might be considered more of an acute than a chronic exposure, however.

\section{Value of Blood Counts to Individuals Exposed to Radiation}

The evidence shows that animal experiments and human experience agree. Radiation exposure at levels greater than, say, 20 times the m.p.d. is likely to produce a real but relatively small drop in neutrophils and/or lymphocytes. How can the clinical pathologist use this information to help the individual ? The temporal variation in the white count of individuals is such that a $30 \%$ fall is to be found at random in $10 \%$ of successive counts (Chamberlain and others, 1952). So when the pathologist finds a low count in someone, gives him a holiday, and then finds his count has come up to normal, it is not legitimate to conclude that the subject had too much irradiation and then recovered. We have also seen that serious aplastic anaemia can occur without necessarily being preceded by much of a decrease in white cells. My own opinion is that blood counts are not of any help to the individual who is working in properly controlled conditions, i.e., in circumstances where there is physical control over the radiation exposure.
Such physical control by film badges and/or radiation meters should be the rule in every hospital. Radiation exposure may nevertheless occur in unexpected ways. Fig. 8 shows the distribution of radiation around a patient with $100 \mathrm{mg}$. of radium in the cervix (Mayneord, 1951). The hands of a nurse making the bed of such a patient may be irradiated by up to 50 m.p.d., so that a few hours' bed-making a week might give her hands the permissible dose. This risk was revealed by a physicist using physical methods.



FIG. 8.-Distribution of radiation around a patient with $100 \mathrm{mg}$. of radium in the cervix. The contours show where 1 and 10 m.p.d. are reached. (Redrawn from Mayneord, 1951.)

Radiation exposure at a place like the Atomic Energy Research Establishment, Harwell, is rigorously controlled. It is in industry in general and especially in universities that people may be very lax about their own protection. For varying reasons they want to get on with their jobs and cannot be bothered-an admirable trait. So Whitby (1949) was able to find definite changes in the blood picture in people working in a university physics laboratory. The weekly dose of his illustrative case was more than 10 times the m.p.d. when the blood changes occurred. In view of our ignorance of the exact relation between radiation dose and change in the blood picture in man it is well worth while to seize every opportunity to investigate individuals in whom exposure is measured physically and is sufficiently frequent or great to lead to blood changes. But it is clear that such exposure is over-exposure and really should not occur. It is perhaps necessary to consider how far the doctor should attempt to protect someone against himself.

Those who are responsible for the clinical care of persons engaged in work with radiation are well 
aware that the worker may fail to carry his film badge, carelessly or deliberately, but that he cannot leave his bone marrow behind him when he goes to expose himself unnecessarily. For someone with clinical responsibility it is a great comfort to feel that there is something which labels the individual and could show up a breakdown in routine protection measures, but the evidence suggests that for radiation workers the comfort provided by blood counts is illusory (Chamberlain and others, 1952). Discussion of morphological changes in blood cells has been deliberately avoided, since there is certainly no general agreement at present that any particular morphological change is characteristic of radiation damage, let alone of harm.

\section{Relation of Marrow Damage to Peripheral Blood Count}

The general picture of the effects of radiation discussed here has some similarity to the effects of drugs toxic to the bone marrow. Sulphonamides, thiourea and its derivatives, and other drugs can produce a serious or fatal aplastic anaemia with little warning. To prevent its occurrence routine white counts at regular intervals are often recommended, but the value of such counts is often called in question, since when the dangerous changes occur their onset is so sudden.

If we are to consider changes in the peripheral blood as evidence of harm to the individual we must believe that the peripheral changes reflect in some way damage to the bone marrow. But is this really an acceptable general principle? Do we believe that someone whose white count is 6,000 per c.mm. has a more active marrow than someone with a count of 5,000 and that the naturally more active marrow will be more resistant to damage by radiation (or drugs)? When there are undoubted changes in the numbers of cells in the peripheral blood due to radiation exposure how can we tell whether the changes were caused by alteration in marrow activity or by some other effect of radiation, and in either case how do we decide that the observed changes indicate harm rather than an acceptable degree of damage? This is one of the questions that have to be faced when considering whether some individuals, especially those whose counts fall at either end of the normal distribution of the population, are peculiarly susceptible to radiation.* Strong views have often been expressed about this, but it is difficult to see how the question can be answered from a consideration of blood counts

\footnotetext{
* Turner (1953) showed that the " natural" sickness rates of those with persistently low white counts were less than those with normal white counts.
}

alone. The only clear evidence of harm to the marrow is the occurrence of serious marrow disease, and aplastic anaemia from radiation stopped occurring in the early 1920 s, since when the m.p.d. has twice been lowered.

This question of how far changes in the peripheral blood reflect damage to the bone marrow or lymph nodes must also be faced when considering the meaning of the reported changes in the average count of a group of people exposed to some fraction or small multiple of the m.p.d. (for summary see Stone, 1952). It is often considered that, even if blood counts are of no value to the individual, the group average of a number of people similarly exposed may reveal over-exposure or radiation damage. Chamberlain and others (1952) found a difference of 124 cells per c.mm. in the mean lymphocyte count of exposed and unexposed workers $(\mathrm{P}<0.02)$. The measured radiation dose in those exposed averaged less than $5 \%$ of the m.p.d. However real in a statistical sense this difference may be, and granted that it is valid to conclude that it was due to radiation and not to some other difference between the two groups, does this difference matter or is it trivial, in the sense in which changes in a gardener's hands may be trivial ? Clearly with larger and larger numbers of counts to average smaller and smaller differences in means become statistically demonstrable, but something outside the statistics is needed to tell whether the differences are meaningful or not.

\section{Harmful Effects of Chronic Irradiation}

It would not be right to give any impression that radiation is not harmful. It must be treated with great respect, not least because the harm sometimes takes 20 years to show itself. Hundreds of cases of malignant disease* have been recorded as caused by radiation (against some 30 of fatal anaemia), and chronic irradiation at dose levels less than that needed to affect the blood count can have markedly damaging effects on the gonads (Fig. 9). This increased sensitivity of the gonads as compared with the blood count seems to be generally true experimentally (for summary see Stone, 1952) and clinically. In the only two human cases of fatal anaemia in which the testis was examined at necropsy, spermatogenesis was found to be completely absent (Gavazzeni and Minelli, 1914; Wegelin, 1930), and in a third case

* Leukaemia is also a consequence of occupational exposure to radiation (March, 1950). In one reported case of leukaemia occurring in a radiation worker where serial blood counts were being occurring in a radiation worker where serial blood counts were being
done (Weitz, 1938) no warning signs of radiation damage were done (Weitz, 1938) no warning signs of radiation damage were
observed, but occupational exposure had been so short that it seems unlikely that the leukaemia was caused by radiation. 
the atrophy was recognized in life long before the onset of the fatal anaemia (Faber, 1923). Some modern Archimedes may develop a technique for waighing the testis in vivo, but until he does gonadal

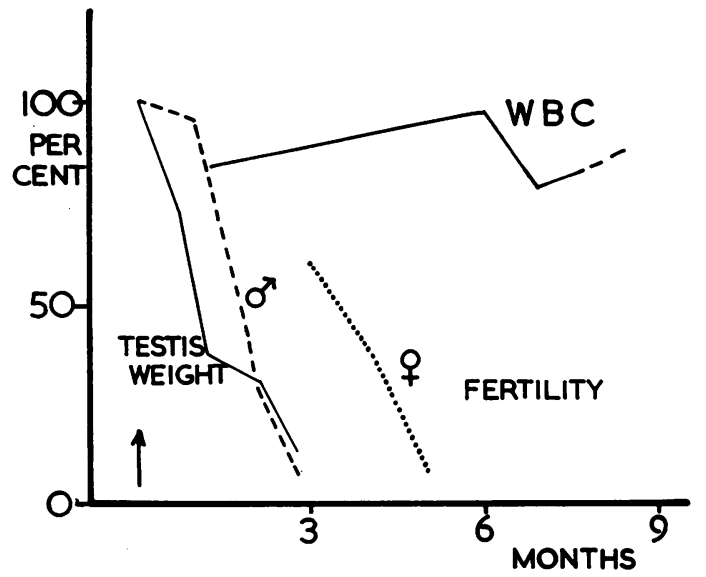

FIG. 9.-Schematic demonstration of effects of chronic neutron irradiation on the white cell count, testis weight, and fertility of male and female mice (Neary, Munson, and Mole, 1954).

damage cannot be easily assessed in man. So that the greater sensitivity of the gonads may be another reason for preferring that radiation hazards should be measured physically rather than controlled by laboratory examination of the exposed individual.

\section{Function of the Clinical Pathologist in Detecting Environmental Hazards}

The doing of blood counts of those exposed to irradiation is just one example of the use of the clinical laboratory in the control of environmental hazards in general. During the last hundred years the bacteriological hazards to health have been steadily decreasing because of public measures of control, measures which do not concern the individual directly. But as civilization increases in complexity, physical and chemical hazards multiply, sometimes quite unexpectedly. Some of these hazards are completely controlled by public measures, but others are controlled by subjecting individuals to laboratory examination, what may be called private or personal control of a hazard. We look for stippled red cells in lead workers, at serum cholinesterase levels in people spraying modern insecticides. These hazards are bound to go on multiplying, and with the increase in number and kind of potential hazard there is bound to be an increase in the laboratory examinations which clinical pathologists will be asked to make. The more clinical pathologists are likely to become involved in this kind of work the more important it is to scrutinize beforehand the evidence that their work will do what it is supposed to do.

Is it true to say that if enough money and care were spent on engineering control of a hazard there would be no need for the clinical pathologist to look for evidence of damage in exposed individuals ? In the atomic energy field it has been repeatedly said about different processes that it would be impossible to arrange the work so that the workers did not get a larger dose of radiation than they should. When the limitation of the irradiation has been insisted on, however, an engineering solution has always been found, though always at some economic cost. At some point someone has to decide, usually on most inadequate evidence, when damage becomes harm, and how much human life and suffering are worth in cash. Something under a thousand men die each year in this country from the occupational risks of mining coal by accidents and pneumoconiosis (Loutit, 1954). The same degree of risk would entail a death from electrocution or irradiation every three to five years amongst the radiologists, radiographers, and hospital physicists of this country. Clearly this amount of risk is not considered reasonable, and one advantage, let us hope, of the development of atomic energy will be a saving of human life in the getting of industrial and domestic power.

\section{Summary}

It is suggested that regular blood counts are of no value to those occupationally exposed to radiation provided there is regular physical measurement of the doses received. The evidence that blood counts are of value has not withstood careful examination. Changes in the peripheral blood by themselves and without further evidence should not be assumed to mirror damage to the bone marrow. Damage to the gonads seems to be a more sensitive index of exposure to radiation.

A clear distinction should be borne in mind between damage and harm; clinical experience is the only guide to the amount of damage which is harmful.

\section{REFERENCES}

Amundsen, P. (1924). Acta radiol., Stockh., 3, 1.

Barclay, A. E., and Cox, S. (1928). Amer. J. Roentgenol., $19,551$.

Carman, R. D., and Miller, A. (1924). Radiology, 3, 408.

Catcheside, D. G. (1950). Practitioner, 165, 590.

Chamberlain, A. C., Turner, F. M., and Williams, E. K. (1952). Brit. J. Radiol., 25, 169.

Cohen, H. (1947). Brit. J. industr. Med., 4, 62.

Edington, G. M., Judd, J. M., and Ward, A. H. (1953). Nature, Lond., $172,122$.

Émile-Weil, P., and Lacassagne, A. (1925). Bull. Acad. Méd., Paris, 93, 237.

Faber, K. (1923). Acta radiol., Stockh., 2, 110. 
Gavazzeni, S., and Mine lli, S. (1914). Strahlentherapie, 5, 309, cited by Wegelin (1930).

Goodfellow, D. R. (1935). Brit. J. Radiol., 8, 669 and 752.

Ingram, M., and Mason, W. B. (1950). UR-121, University of Rochester Atomic Energy Project Report.

Judd, J., and Ward, A. H. (1954). Personal communication.

Lambin, - (1930). Arch. Elect. méd., 38, 497.

Larkins, F. E. (1921). Arch. Radiol. Electrother., 25, 380.

Lavedan, J. (1929). Radiophysiol. et Radiothér., 1, 477.

Lorenz, E., Eschenbrenner, A. B., Heston, W. E., and Uphoff, Delta (1951). J. nat. Cancer Inst., 11, 947.

Heston, W. E., Jacobson, L. O., Eschenbrenner, A. B., Shimkin, M., Deringer, M. K., and Doniger, J. (1946). MDDC-655, Manhattan District Declassified Report. U.S.A.

Loutit, J. F. (1954). J. Atom. Scient. Ass., 3, 321.
March, H. C. (1950). Amer. J. med. Sci., $220,282$.

Mayneord, W. V. (1951). Brit. J. Radiol., 24, 525.

Mottram, J. C. (1920). Arch. Radiol. Electrother., 25, 194.

(1921). Ibid., 25, 368.

(1931). Lancet, 1, 42

Neary, G. J. (1952). In Biological Hazards of Atomic Energy, ed. A. Haddow, p. 101. Clarendon Press, Oxford.

— Munson, R. J., and Mole, R. H. (1954). Unpublished.

Recommendations of the International X-ray and Radium Protection Commission (1932). Brit. J. Radiol., 5, 82.

Stone, R. S. (1952). Radiology, 58, 639.

Turner, F. M. (1953). Brit. J. Radiol., $26,417$.

Wegelin, C. (1930). Beitr. path. Anat., 84, 299.

Weitz, W. (1938). Klin. Wschr., 17, 1579.

Whitby, L. E. H. (1949). J. roy. Inst. publ. Hlth, 12, 19, 54, and 88. 